\title{
SIMULATION OF FUEL ECONOMY FOR MALAYSIAN URBAN DRIVING
}

\author{
M.A. Abas ${ }^{1,2}$, M.F. Muhamad Said ${ }^{2, *}$, S.F. Zainal Abidin ${ }^{1,2}$ and I. Zahari ${ }^{1,2}$ \\ ${ }^{1}$ Proton Holdings, Section 26, 56000 Shah Alam, Selangor, Malaysia. \\ ${ }^{2}$ Automotive Development Centre, Faculty of Mechanical Engineering, \\ Universiti Teknologi Malaysia, UTM Johor Bahru, Malaysia \\ Email: mfarid@fkm.utm.my \\ Phone: +6075535449; Fax: +6075535811
}

\begin{abstract}
By understanding the implications of real-world driving conditions, improved fuel economy via a strategy of key technologies can be implemented to assist fuel economy validation during development programs. Vehicles in real-world driving conditions regularly travel at idle, low and medium speeds, particularly for urban driving, and this has a crucial weight in overall vehicle fuel economy, given the residencies at the lower engine speed and load region. This paper presents the validation of the derived engine conditions representing Malaysian actual urban driving in an attempt to formulate representative fuel economy data. The measurements were conducted through on-road urban driving within Kuala Lumpur to establish representative driving conditions. The effectiveness of the proposed conditions was then validated in terms of fuel economy using a simulation. The discrepancy between the fuel economy in the proposed conditions and the real-world measurements has improved, falling to $11.9 \%$ compared to $43.1 \%$ reported by the NEDC.
\end{abstract}

Keywords: Urban; real-world; driving conditions; fuel economy.

\section{INTRODUCTION}

Studies of on-the-road driving have been conducted globally, mainly to understand the real-world conditions prior to developing a representative drive-cycle. Drive-cycles are important in evaluating the emissions from road transport in order to comply with stringent challenges from governing bodies such as the EPA [1] and the European Union [2]. The European Union is keen to develop and update test procedures which include realistic conditions in emission measurement from vehicles [3]. Funded by the European Commission, the Assessment and Reliability of Transport Emission Models and Inventory Systems project, known as ARTEMIS, has derived a reference driving cycle intended to improve testing methodologies and extend the database of pollutant emissions [4]. But even with the transient conditions that can be found in the current drive-cycles, the emission measurements are still found to differ from actual traffic conditions [5].

In general, a drive-cycle in the legislation is a procedure that consists of a vehicle's speed trace against time that the driver needs to follow. Adherence to the drive-cycle procedure requires a vehicle to idle, accelerate, decelerate and cruise at steady-state. If the procedures are conducted in laboratories, the ambient temperature parameters are controlled [6]. These drive-cycles were purposely generated to be simple enough to allow for high repeatability. Drive-cycles are also used by vehicle 
manufacturers during the earlier development phase mainly to evaluate the status of fuel economy. Furthermore, in cases where a vehicle platform is unavailable during the earlier development phase, manufacturers conduct engine validations on a test bench using the drive-cycles as the testing conditions to provide an understanding of fuel economy under actual driving conditions. However, drive-cycles are known to have discrepancies in the fuel economy and emission results compared to actual driving conditions [7-10]. Some of the main reasons for these discrepancies are the generalization of drive-cycles to cover a wide range of driving conditions and the evolution of other factors such as technologies and infrastructures. In actual driving, the conditions are far more complex due to the influence of other factors such as traffic congestion, weather and even the local driving culture. Therefore, the main aim of this study is to validate the conditions representing actual Malaysian urban driving in an attempt to formulate representative fuel economy data. Using a vehicle simulation, the validity of the established actual conditions is then proven with the correlation of the fuel economy.

Available studies conducted on actual driving conditions have produced many driving cycles across the world through several techniques. The 'micro-trip' or 'kinematic sequence' is a common process among the applied techniques. The microtrip uses the vehicle speed trace between two successive vehicle stops [11]. The vehicle speed profiles recorded from actual driving are broken down into smaller segments known as sequences. These sequences are then categorized by a selection of variables such as average speed, stop duration, acceleration and fuel economy. However, since the main intention of this study is to establish representative engine conditions and not to produce a drive-cycle yet, the micro-trip process was not applied. Instead, the raw samples from the data collection were directly analyzed using a clustering technique. A previous study by the authors identified that the NEDC adopted in Malaysia's legislation shows discrepancies in representing Malaysian driving conditions. Figure 1 shows that the range of engine speed and engine torque derived from actual driving conditions is wider than the NEDC by $75 \%$ and $64 \%$ respectively.

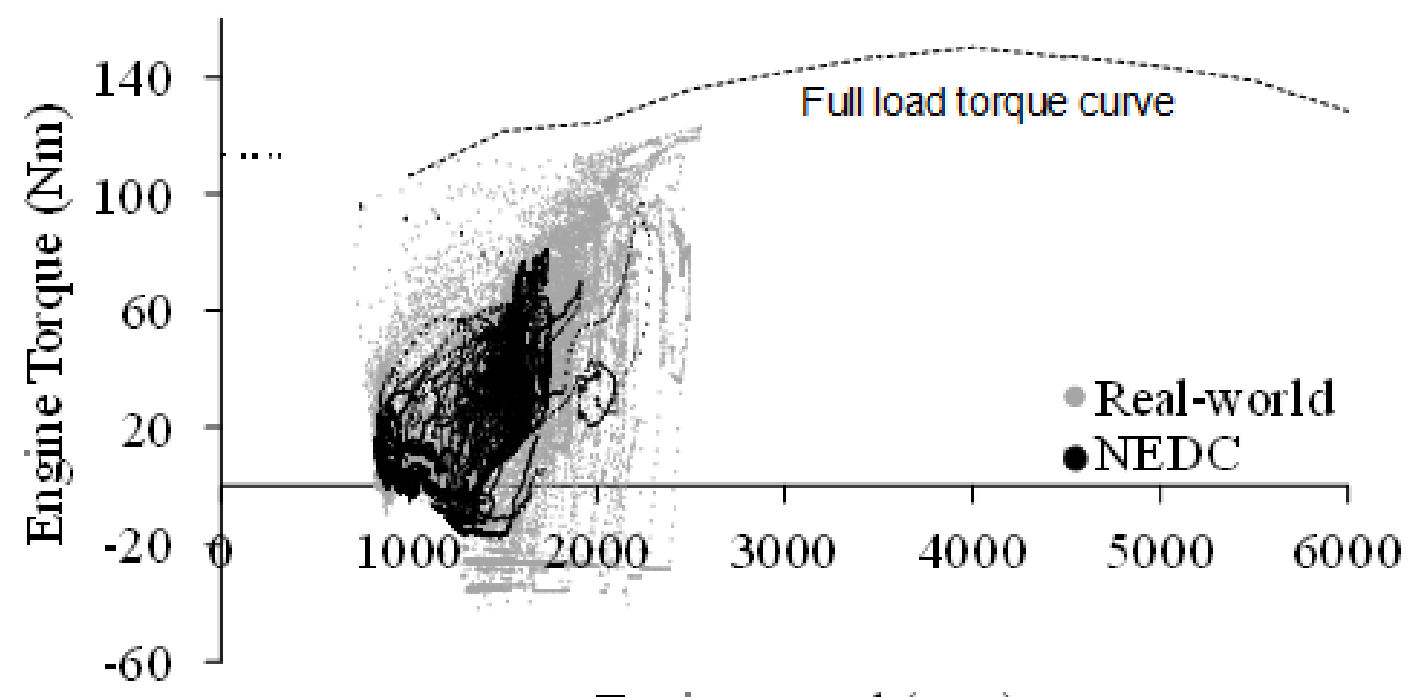

Engine speed (rpm)

Figure 1. Engine speed and engine torque during actual urban driving and NEDC. 
Table 1 shows the statistics of actual driving and the NEDC, and highlights the differences of vehicle variables, based on which the engine variables are expected to behave accordingly. The above discrepancies are believed to be the cause of the differences between the values of average fuel economy from actual driving and the NEDC. The NEDC average fuel economy was understated by $43.1 \%$ below the actual conditions, which leads to misunderstandings for manufacturers during the development phase and misleading information for consumers during actual driving. The significant difference in the average fuel economy has motivated this study to establish engine conditions that will be representative of actual driving conditions, particularly in Malaysian urban driving, that can be applied in manufacturers' engine development programs.

Table 1. Statistics of actual driving and NEDC.

\begin{tabular}{clccc}
\hline No. & Variables & [Unit] & Actual & NEDC \\
\hline 1 & Percentage of time driving & $\%$ & 64.25 & 79.58 \\
2 & Percentage of time standing & $\%$ & 35.75 & 20.42 \\
3 & Average speed & $\mathrm{km} / \mathrm{h}$ & 17.56 & 33.6 \\
4 & Average driving speed & $\mathrm{km} / \mathrm{h}$ & 27.33 & 42.24 \\
5 & Standard deviation of speed & $\mathrm{km} / \mathrm{h}$ & 24.72 & 28.91 \\
6 & Maximum speed & $\mathrm{km} / \mathrm{h}$ & 100.00 & 120.09 \\
7 & Average acceleration & $\mathrm{m} / \mathrm{s}^{2}$ & 0.0 & 0.0 \\
8 & Standard deviation of & $\mathrm{m} / \mathrm{s}^{2}$ & 0.5 & 0.4 \\
& acceleration & Liter/100 & \multirow{2}{*}{14.17} & 8.06 \\
\hline
\end{tabular}

\section{METHODS AND MATERIALS}

\section{Test Vehicle and Instrumentation}

A 1.6L passenger car with specifications shown in Table 2 was used as the test vehicle for this study. Prior to the test, the car was instrumented and prepared according to the manufacturer's standards and specifications.

Table 2. Subject vehicle specification.

\begin{tabular}{ll}
\hline Subject & Specification \\
\hline Vehicle type & Passenger car, 4-doors, FWD \\
Vehicle curb & $1,027 \mathrm{~kg}$ \\
weight & $10,210 \sim 10,400 \mathrm{~km}$ \\
Vehicle mileage & $\mathrm{CVT}$ \\
Transmission & $185 / 60 \mathrm{R} 14$ \\
Tire size & $\begin{array}{l}1.6 \mathrm{~L}, 4-\mathrm{cylinder} \text { PFI inline, max. torque } 150 \mathrm{Nm}, \max . \\
\text { power } 80 \mathrm{~kW}\end{array}$ \\
\hline
\end{tabular}


A data acquisition system which uses a non-contact speed and distance measurements using GPS was installed on the test vehicle to measure the vehicle speed, acceleration and distance during the actual driving. In measuring the torque, 'wheel force transducer' equipment which consisted of strain gauges was mounted on a special wheel hub. The signals are conditioned by a slip ring attached to the hub and transmitted to the data acquisition via cable. A fuel flow meter was installed into the fuel line to measure instantaneous fuel economy. While other studies [12-14] use measured intervals between $1 \mathrm{~Hz}$ and $100 \mathrm{~Hz}$ to record variables during actual driving conditions, this study measured the variables at $100 \mathrm{~Hz}$.

\section{Route Selection}

According to the Ministry of Transportation Malaysia [15], the state of Kuala Lumpur has the highest number of registered passenger vehicles in the country. With a consistent growth from 2010, Kuala Lumpur holds the majority of $32 \%$ of the total of 10.18 million passenger vehicles in Malaysia as of December 2012, followed by the states of Johor, Selangor, Penang and others. The Department of Statistics also reported that Kuala Lumpur has the highest population density in Malaysia, reaching 6,891 persons per square $\mathrm{km}$ in 2010 [16]. Therefore, Kuala Lumpur was chosen as the area of study in which the selected routes represent Malaysian urban driving. Considering many driving aspects such as traffic congestion, short drive stints and highway driving, the Kuala Lumpur area was further narrowed to focus on the central routes known regularly to have high congestion conditions during peak hours. Live traffic congestion within the area of study was periodically observed using Google Map, which plots live traffic sites using a crowd-sourcing technology, a method utilizing actual traffic data contributed by GPS users [17]. Based on the observation, the specific routes of actual driving within the area were determined, encompassing smooth traffic, slow traffic, stationary traffic and highway driving. The test was focused on weekdays, between 0730 and 1030 hours.

\section{Driving Technique}

The test vehicle was driven towards a starting point within the selected urban area, and then the data logging was activated. With the air-conditioning and radio turned on, the test was conducted with a co-driver on board to constantly monitor the real-time data and also for additional weight for the vehicle. In terms of driving pace along the route, the test vehicle was driven as a 'chase car', a method adapted from [18]. The chase car method chooses a vehicle to follow for as long as possible within the area of study, duplicating the chosen vehicle's operations at a constant distance. If the chosen vehicle drives out of the area of study, the chase car immediately chooses a new vehicle to

follow. For this research, a passenger car was to be chosen at the starting point, to be followed as long as the chosen car drives on the selected route; otherwise a new vehicle will be chosen.

\section{Analysis Method}

The TwoStep clustering method by SSPS was used [19] as it has the capability to process a large number of samples. Variables collected from the actual driving were statistically analyzed to understand the impact on the engine conditions under urban driving conditions. Using the clustering technique, the actual engine conditions were 
clustered, thus producing cluster centers which represent the mean of the conditions. The TwoStep cluster analysis consists of two steps in which the first step preliminarily clusters the cases into small sub-clusters using a sequential approach. Based on the distance criterion, each item of data is either merged with a previously formed cluster or starts a new cluster. The second step involves clustering the sub-clusters produced from the first step until the desired numbers of clusters are achieved using a hierarchical algorithm. To measure the distance between clusters, the Euclidean distance as expressed in Eq. (1) was used for this study.

$$
D_{i j}=\sqrt{\sum_{k=1}^{n}\left(x_{k i}-x_{k j}\right)^{2}}
$$

where $D_{i j}$ is the distance between cases $i$ and $j ; x_{k i}$ value of variable $X_{k}$ for case $j$

To automatically determine the optimal number of clusters for the analysis, the BIC (Schwarz's Bayesian Information Criterion) indicator was used. For J clusters, the BIC indicator was computed according to Eq. (2) as follows:

where:

$$
B I C(J)=-2 \sum_{j=1}^{J} \varepsilon_{j}+m_{j} \cdot \log (N)
$$

$$
m_{j}=J\left\{2 K^{A}+\sum_{k=1}^{K^{B}}\left(L_{k}-1\right)\right\}
$$

where $K^{A}$ is the total number of continuous variables; $K^{B}$ is the total number of categorical variables; $L_{k}$ is the total number of categories for the $k$-th categorical variable.

\section{RESULTS AND DISCUSSION}

\section{Clustering Analysis}

Some other areas of study have clustered samples according to a pre-selected number. This study, however, does not have a selected number of clusters because the purpose of clustering here is to identify and highlight the important conditions. To determine the engine conditions during actual driving, engine speed and engine torque were selected as the variables to be clustered. Based on the equation rules above, the TwoStep cluster analysis automatically produces five clusters. The cluster centers are the vector of the cluster means of each variable input, as shown in Table 3 . The vehicle speed and fuel consumption are from the mean of the clusters.

Table 3. Variables of the generated clusters.

\begin{tabular}{lccccc}
\hline & \multicolumn{5}{c}{ Clusters } \\
\cline { 2 - 6 } Variables & 3 & 1 & 5 & 2 & 4 \\
\hline Size [\%] & 66.7 & 22.0 & 6.9 & 3.5 & 0.9 \\
Mean engine speed [rpm] & 967 & 1,587 & 2,023 & 1,663 & 1,366 \\
Mean engine torque [Nm] & 6.45 & 42.33 & 83.32 & -21.85 & 78.02 \\
Mean vehicle speed [km/h] & 5.93 & 32.03 & 62.79 & 60.28 & 15.13 \\
Mean fuel consumption & 38.64 & 85.59 & 176.11 & 18.99 & 112.39 \\
{$[\mu \mathrm{l} / 100 \mathrm{~ms}]$} & & & & & \\
\hline
\end{tabular}


Figure 2 shows the total sampling of the engine speed and torque conditions logged during actual urban driving. Based on the Euclidean distance, Cluster 3, highlighted in Figure 2, has the largest member population of $66.7 \%$ from the total of 58,599 samples with a mean vehicle speed of $5.93 \mathrm{~km} / \mathrm{h}$, followed by Cluster 1 with a mean vehicle speed of $32.03 \mathrm{~km} / \mathrm{h}$, which are within the common vehicle speed region for urban traffic $[5,20,21]$. The cluster size trend shows a large ratio between Cluster 3 and other clusters, which also highlights the importance of Cluster 3 as the main condition in actual urban driving. Members of Cluster 3 represent the lower engine speed region with a torque range between -40 and $60 \mathrm{Nm}$. The higher torque at engine speed below 1,000 rpm within Cluster 3 depicts the vehicle's standing start acceleration, while the negative torque above 1,000 rpm represents deceleration by engine braking.

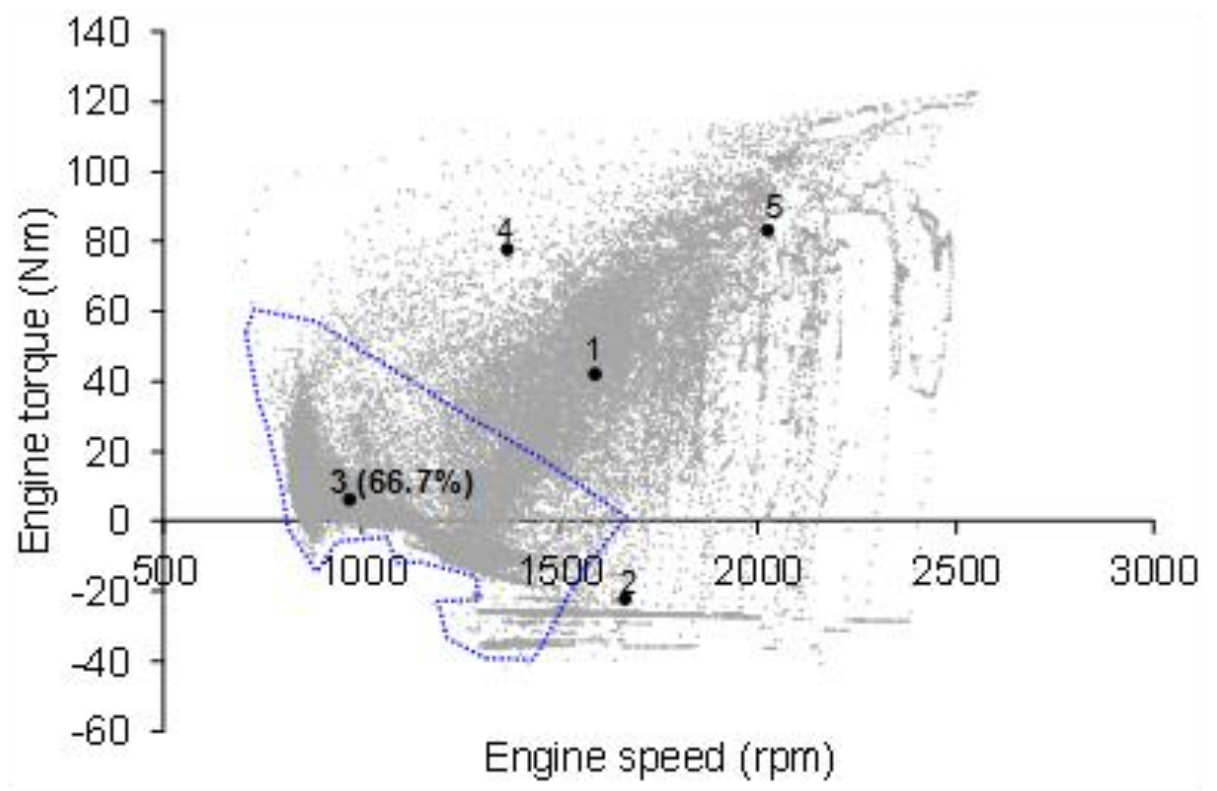

Figure 2. Clusters within Malaysian actual urban driving.

\section{Vehicle Modeling}

In an attempt to assess the performance of the baseline vehicle as well as to explore potential fuel economy measurement over the clusters, the modeling work is split into two sections. The first section is aimed at establishing a correlated baseline vehicle model. This is achieved by performing a vehicle simulation and validating the output against the actual fuel economy measurements. An engine model was developed together with results obtained from an engine bench test. The developed engine model produces a fuel consumption map in brake specific fuel consumption (BSFC), as shown in Figure 3, which is used to evaluate engine operation. Various quantities are visualized by the curves, which are a function of static engine speed and engine torque. The BSFC varies substantially along and between the power hyperbolas. The upper envelope of the map is the full load performance curve. Points below this curve define the part-load operating characteristics. As can be seen from Figure 3, the best fuel consumption is achieved within the region at lower engine speed while producing higher torque, where the engine operates with its maximum efficiency. As the engine 
conditions move away from this region, the fuel consumption starts to depreciate. Poor fuel consumption values are shown across the engine speeds with lower torque.

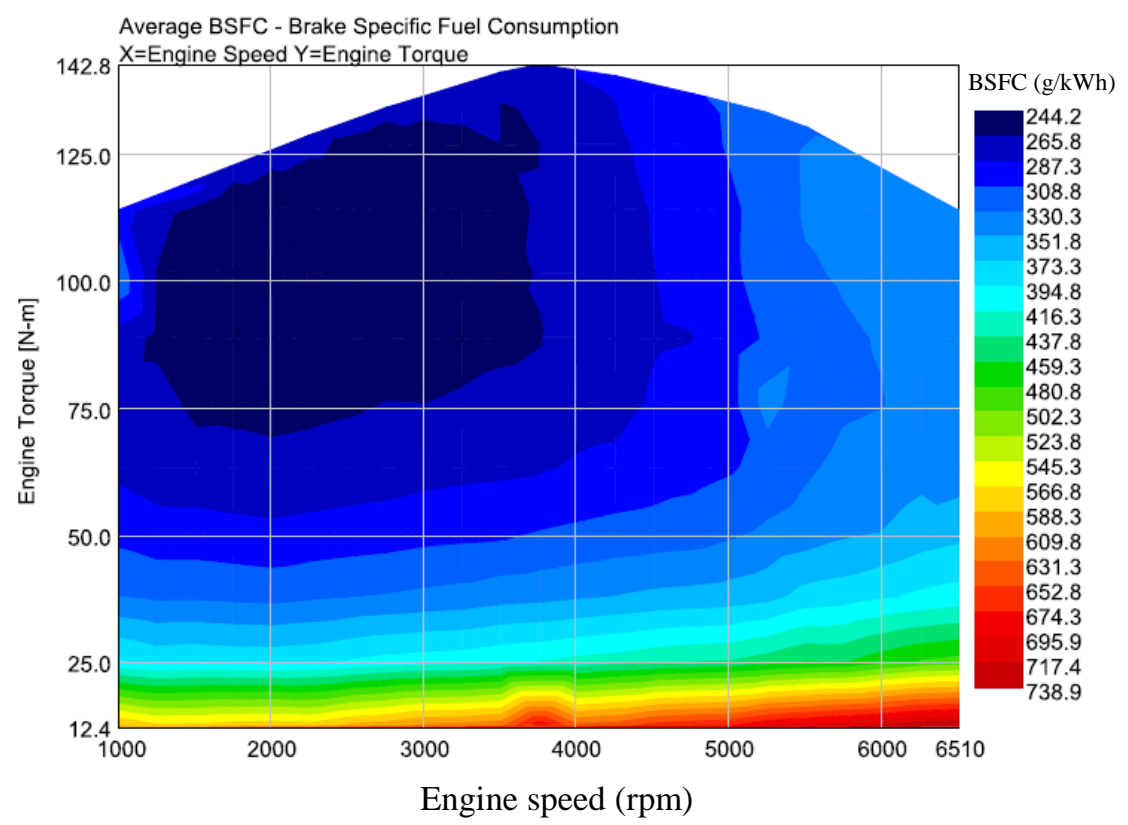

Figure 3. Fuel economy map derived from the engine model.

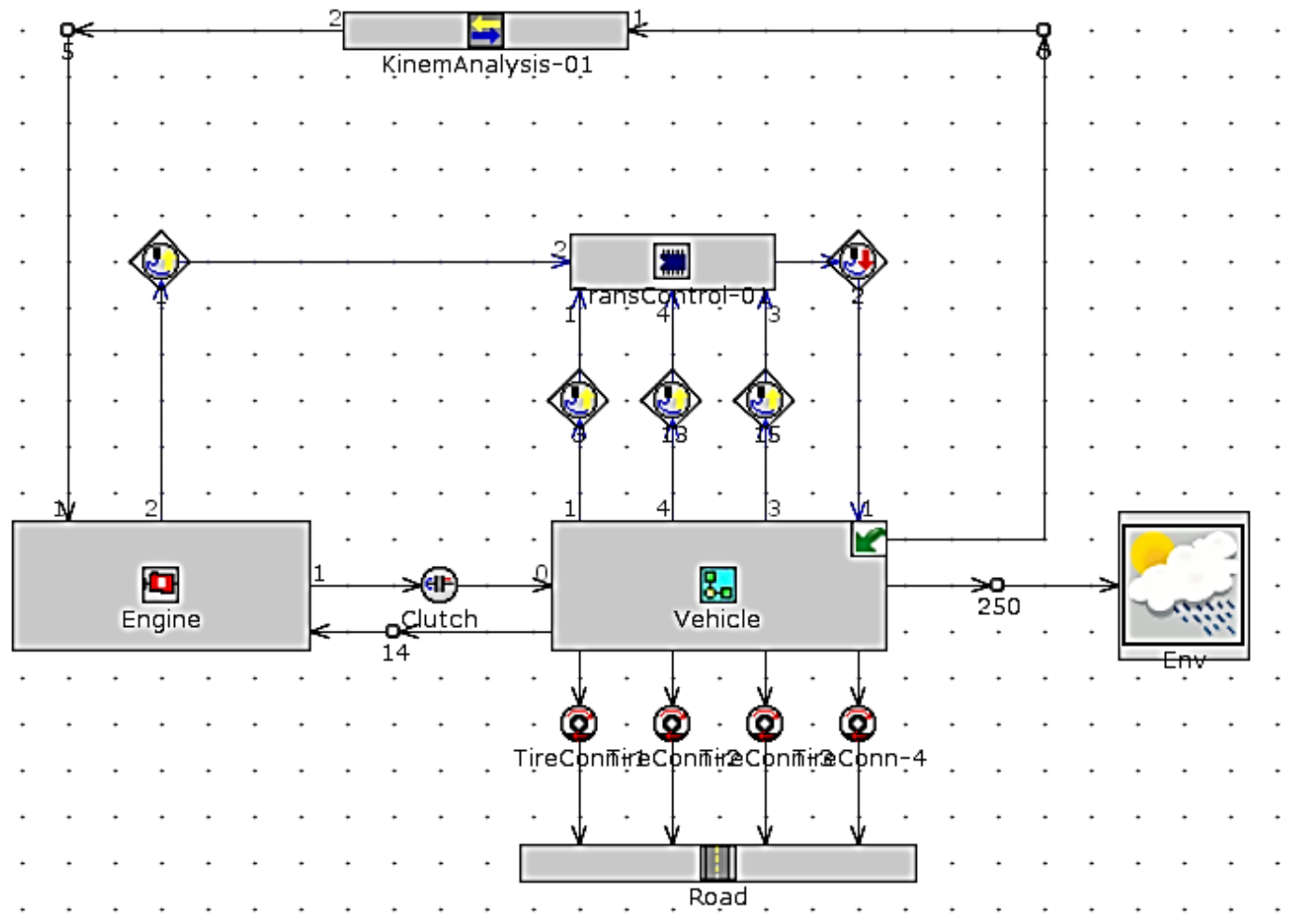

Figure 4. Simulation model developed as an input to the vehicle model simulation. 
The established engine model was then used in the vehicle model shown in Figure 4 . The modeling work involves a basic transient part-load simulation based on actual driving. The engine speed and torque obtained from on-board measurements were imposed as transient target profiles for the model. A PID-based controller element was included in the model to adjust the throttle opening according to the transient torque demand. The fuel economy comparison between the simulation and actual driving was correlated using the actual driving characteristics to produce the results shown in Figure 5. The variation of fuel economy measured between routes is mainly due to the different driving conditions, such as average traveling speed, stop frequency and stop duration. The fuel economy results derived from the simulation differ from the actual driving by between $-2.9 \%$ and $2.5 \%$.

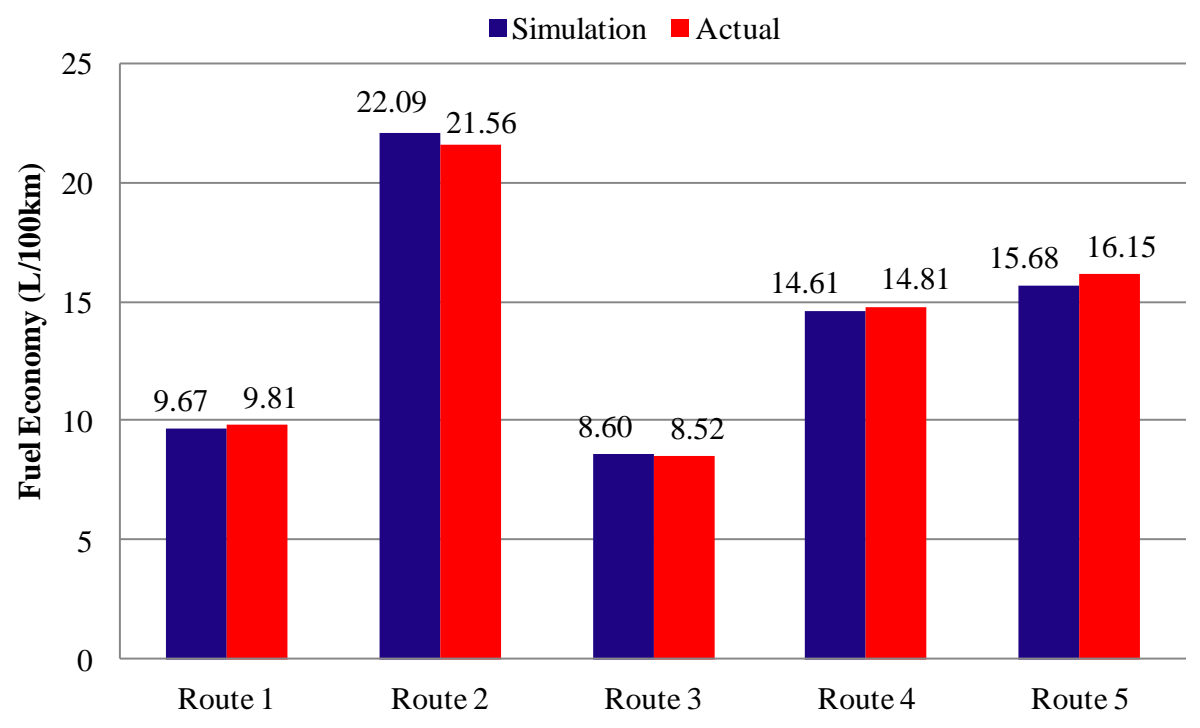

Figure 5. Fuel economy comparison between vehicle simulation and actual driving.

The second section is aimed to validate the means of the clusters in representing Malaysian urban driving using the correlated vehicle model. With the intention of obtaining a simplified and repeatable cycle without visiting all conditions in the total samples, a steady-state cycle is proposed using the means of each generated cluster. The means used in the proposed cycle are used to represent the members of respective clusters. The means were arranged according to the size of each cluster to represent the segments of the total duration, as shown in Figure 6. A large proportion of the proposed cycle consists of means from the large clusters: Cluster $3(66.7 \%)$ and Cluster 1 (22.0\%). The vehicle simulation was conducted by having the proposed cycle in terms of engine speed and torque as the target variables. The vehicle simulation produced a fuel economy of 12.48 liters $/ 100 \mathrm{~km}$ over the proposed cycle. However, the proposed cycle still lacks consideration of factors related to engine cold start and transient behavior, which inevitably have an influence on the vehicle fuel economy. On the other hand, the proposed cycle is easily applied for conventional engine bench testing to simulate Malaysian urban driving.

Table 4 shows the comparison of average variables of the actual, NEDC and the proposed conditions. The variations of average variables from the proposed conditions have improved over the NEDC to represent actual Malaysian urban driving conditions. The average fuel economy produced by the NEDC differed by $-43.1 \%$ from actual 
Malaysian urban driving conditions but the average fuel economy from the vehicle simulation on the proposed conditions has reduced the difference to $-11.9 \%$.

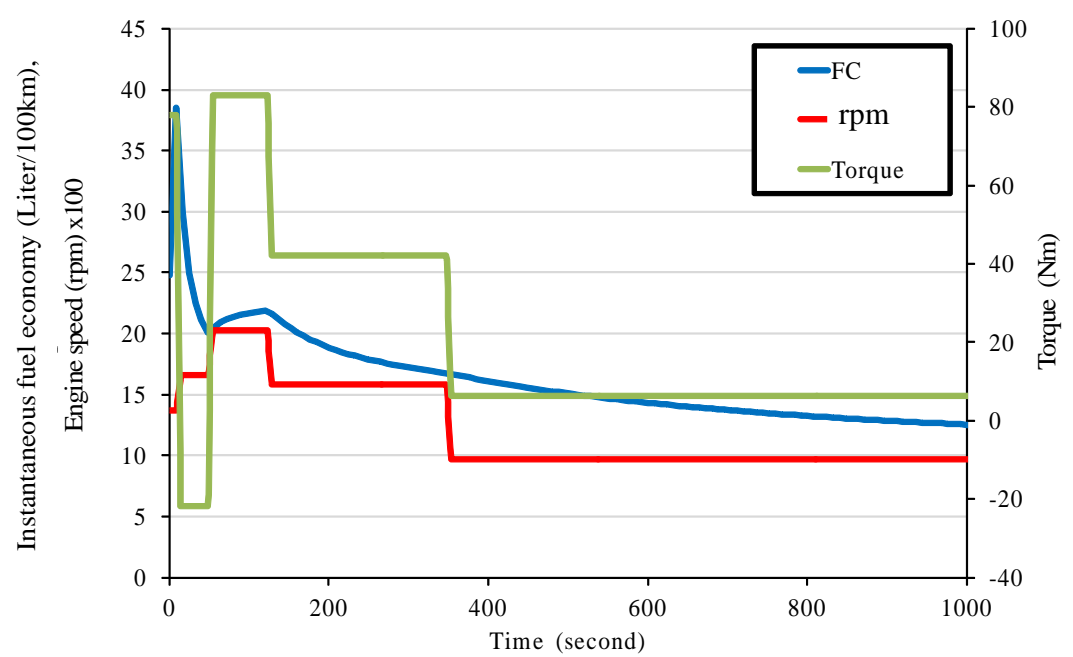

Figure 6. Fuel economy over the proposed cycle.

Table 4. Fuel economy between actual, NEDC and proposed cycles.

\begin{tabular}{lcccc}
\hline Variables & Unit & Actual & NEDC & Proposed \\
\hline $\begin{array}{l}\text { Average vehicle } \\
\text { speed }\end{array}$ & $\mathrm{km} / \mathrm{h}$ & 17.6 & 33.6 & 17.6 \\
$\begin{array}{l}\text { Average engine } \\
\text { speed }\end{array}$ & $\mathrm{rpm}$ & $1,203.3$ & $1,429.6$ & $1,203.8$ \\
$\begin{array}{l}\text { Average engine } \\
\text { torque }\end{array}$ & $\mathrm{Nm}$ & 18.3 & 25.5 & 19.3 \\
$\begin{array}{l}\text { Average fuel } \\
\text { economy }\end{array}$ & Liter/100km & 14.17 & $\begin{array}{c}8.06 \\
(-43.1 \%)\end{array}$ & $\begin{array}{c}12.48 \\
(-11.9 \%)\end{array}$ \\
\hline
\end{tabular}

\section{CONCLUSIONS}

Samples from actual Malaysian urban driving were collected and analyzed. The driving conditions from the samples were clustered into five areas. These five clusters summarize the engine conditions used as the initial proposal to best represent the Malaysian urban driving conditions. Simulation work was conducted to validate the proposed conditions in terms of fuel economy. The simulation model was correlated against actual urban driving to ensure that the fuel economy produced by the simulation was accurate. The correlated model was then used on the proposed conditions. The simulation results show that the proposed driving conditions improve on the NEDC in terms of fuel economy measurements, and are feasible to use within engine development programs on the engine test bench to measure the fuel consumption for Malaysian urban driving. Nevertheless, there are still many possible improvements that could be applied on the proposed conditions through the extension of data analysis and simulation parameters to further improve the accuracy of the proposed conditions.

Several areas will be explored in the attempt to further improve the accuracy of fuel economy measurement. One such area is to explore the breakdown of actual driving profiles into micro-trips which can then be analyzed by including acceleration-related 
variables prior to the clustering. With consideration of acceleration-related variables, transient conditions can also be explored. Another area to investigate is the application of simulation parameters such as cold start, ambient temperature, air intake temperature and relative humidity, which were set to a nominal value for the current work. In reality, these parameters vary depending on the driver, time, traffic conditions, road conditions, weather and location, all of which have an influence on the fuel economy.

\section{ACKNOWLEDGMENT}

The authors acknowledge the financial support from Universiti Teknologi Malaysia and Ministry of Higher Education Malaysia (MOHE) under the FRGS grant R.J130000.7809.4F174.

\section{REFERENCES}

[1] Kraft M, Maigaard P, Mauss F, Christensen M, Johansson B. Investigation of combustion emissions in a homogeneous charge compression injection engine: Measurements and a new computational model. Proceedings of the Combustion Institute. 2000;28:1195-201.

[2] Heywood JB. Internal combustion engine fundamentals: Mcgraw-hill New York; 1988.

[3] Favre C, Bosteels D, May J. Exhaust emissions from european market-available passenger cars evaluated on various drive cycles. SAE Technical Paper No. 2013-24-0176; 2013.

[4] André M. The ARTEMIS European driving cycles for measuring car pollutant emissions. Science of the Total Environment. 2004;334:73-84.

[5] Armas O, Garcia-Contreras R, Ramos A. Emissions of light duty vehicle tested under urban and extraurban real-world driving conditions with diesel, animal fat biodiesel and GTL fuels. SAE Technical Paper No. 2013-24-0176; 2013.

[6] Regulation No. 101. In: UNECE, editor.: United Nations Economic Commission for Europe 2013.

[7] Vojtisek-Lom M, Fenkl M, Dufek M, Mareš J. Off-cycle, Real-world emissions of modern light duty diesel vehicles. Consiglio Nazionale delle Ricerche; 2009.

[8] Lee JH, Gitano H, Eu HS, Mohd Khalil AS. Development of motorcycle drive cycles for Malaysia. SAE Technical Paper No. 2010-32-0041; 2010.

[9] Oropeza RG, S.Samuel, Hassaneen AE, Morrey D. Evaluation of fuel consumption and exhaust emission levels from a EURO-IV vehicle for realworld driving in Mexico city. SAE Technical Paper No. 2009-01-1824; 2009.

[10] Wi H, Park J, Lee J-h, Kim W, Kim Y. Development of a city bus driving cycle in seoul based on the actual patterns of urban bus driving. SAE Technical Paper No. 2009-01-2914; 2009.

[11] André M, Joumard R, Hickman AJ, Hassel D. Actual car use and operating conditions as emission parameters: derived urban driving cycles. Science of the total environment. 1994;146:225-33.

[12] Ericsson E, Mocsári T, Rapone M, Brundell-Freij K. Variability in driving patterns over street environments in three European cities. 4th International Symposium Transport and Air Pollution, Austria. 2005; 1-6 
[13] Li H, Andrews GE, Daham B, Bell M, Tate J, Ropkins K. Impact of traffic conditions and road geometry on real world urban emissions using a SI car. SAE Technical Paper No. 2007-01-0308; 2007.

[14] Bratt H, Ericsson E. Measuring vehicle driving patterns-estimating the influence of different measuring intervals. Urban Transport Systems Proceedings from the 2nd Research Conference in Lund, Sweden, 2000.

[15] Ministry of Transportation M. Total Motor Vehicles by type and state, Malaysia. Road Transport Department; 2013.

[16] Department of Statistics M. Population distribution and basic demographic characteristics. From https://www.statistics.gov.my/

[17] Barth D. The bright side of sitting in traffic: Crowdsourcing road congestion data. From http://googleblog.blogspot.com/2009/08/bright-side-of-sitting-intraffic.html; 2009.

[18] Johnson TM, Formenti DL, Gray RF, Peterson WC. Measurement of motor vehicle operation pertinent to fuel economy. SAE Technical Paper 750003; 1975; 1-30.

[19] Luo JY, Shao PJ, Bin L. Research on characters of operations in EMS Base on clustering techniques. Second International Conference on Information and Computing Science, IEEE. 2009; 217-20.

[20] Imaizumi H, Sengoku K. Estimation of $\mathrm{CO}_{2}$ Reduction potential in Japan by traffic-flow smoothing and eco-driving promotion. SAE Technical Paper; 2013.

[21] Fotouhi A, Montazeri-Gh M. Tehran driving cycle development using the kmeans clustering method. Scientia Iranica. 2013;20:286-93. 